\title{
Development of an Augmented Feedback Application to Support Motor Learning after Stroke: Requirement Analysis
}

\author{
Simone Schmid* \\ Berlin Institute of Technology, Center of Human-Machine Systems, \\ Research Training Group prometei, \\ Franklinstr. 28-29, 10587 Berlin, Germany
}

\begin{abstract}
The introduction of robotic and mechatronic devices in motor rehabilitation after stroke offers new possibilities to support the relearning of motor skills. One of these new fields in rehabilitation research is the visual augmentation of movement-related parameters. So far, the effects of augmented feedback on the learning outcome are only vaguely assessed and more clinical studies are needed. This paper describes the first step of a user-centered approach to develop visually augmented feedback applications for the use in clinical studies.
\end{abstract}

Keywords: augmented feedback, motor learning, neurorehabilitation, stroke, requirement analysis, human-centered design.

\section{Introduction}

Stroke is the leading cause of adult disability [27]. Each year, approximately 780,000 individuals in the United States and 250,000 in Germany suffer from the aftermath of stroke 22]. The most prevalent consequences of stroke are motor deficits like hemiparesis. Hemiparesis is amongst others characterized by abnormal muscle tone, postural adjustments and movement synergies, incorrect timing within movement patterns, loss of inter-joint coordination, and loss of sensation 6]. These impairments affect the patients' quality of life and their ability to perform activities of daily living. The prospect of returning to an independent life after stroke can be increased by an early motor therapy. The recovery of motor functions is a drawn-out process based on intensive, task-specific and repetitive movement training, supported by manual as well as device-assisted therapy [20]. This project focuses on the recovery of the upper extremity (UE) because arm and hand dysfunctions persist for many years after the stroke 22$]$.

The introduction of device-assisted motor rehabilitation allows recording, analyzing, extracting and presenting data about the current movement on- and off-line. Information about pathological movement patterns, deviations of trajectories and/or force profiles can be quantified and automatically fed back to the

\footnotetext{
* This work was supported by the Research Training Group prometei at TU Berlin
} funded by the German National Science Foundation (DFG). 
patients. The presented movement-related parameters, also referred to as augmented feedback, could serve as a basis for error correction and thereby facilitate motor learning 15 .

So far, effects of augmented, visual feedback on re-learning of motor skills after stroke have not been elaborated. Before any further investigations can take place, feedback visualizations must be developed that can be perceived and processed by the patients. This is especially true because $56.6 \%$ of the stroke survivors are seriously affected by cognitive deficits such as disturbances of attention and executive dysfunction [23, [12].

This paper describes the user-centered development approach of the graphical feedback application tailored to the needs of stroke patients. For that, the importance of augmented feedback for motor learning after stroke is outlined. Results of the requirement analysis are reported and conclusions in the form of project-specific usability goals and design principles are presented.

\section{Relevance of Augmented Feedback in Motor Rehabilitation after Stroke}

Besides practice, augmented feedback is one of the most powerful factors identified to influence motor learning in healthy individuals [15], [16]. In contrast to inherent feedback that naturally results from the execution of movements, augmented feedback is provided by an an external source. Inherent feedback is considered as complex and hard to interpret, whereas augmented feedback can emphasize important movement aspects individually [24. There are different facets of augmented feedback such as modality, frequency, scheduling and content affecting the learning outcome dependent on the complexity of the movement to be learned, the learners skill level and the context.

The same influencing variables on motor learning in healthy individuals and stroke patients can be supposed due to the assumption of similar learning mechanisms [29]. For example, feedback can be used to reduce movement errors because it shapes neural activity in motor and premotor areas [1]. Single unit recordings demonstrate that visual information can have effects on neural circuits and therefore provide a potent signal for reorganization of sensorimotor circuits [13. Some researches suggest that stroke patients could even benefit more from adequately presented augmented feedback than healthy individuals [9]. They reason that stroke patients are not able to use intrinsic or proprioceptive feedback because of the cognitive, perceptual and sensation impairments and need supplementary information.

There are many systematic studies about the effects and mechanisms of feedback in healthy individuals. The increasing number of reviews about augmented feedback after stroke published in the last few years reflects the importance of feedback in neurorehabilitation (see i.a. [28, [7], 26]). Besides, the reviews indicate that the used materials for feedback presentation are neither standardized nor guarantee the suitability for stroke patients. 


\section{Development Process}

The development of the graphical feedback application follows the rationale of user-centered design (UCD). UCD focuses on the user demands through planning, design and development. For this, findings from the field of software ergonomics, in turn obtained from disciplines like computer sciences, linguistic, psychology and sociology are adapted to the particular needs of the users. The core objective is to design easy to use products, allowing an optimal interaction according to a pleasurable user experience [18].

One approach to UCD is usability engineering which provides explicit methods to develop software that corresponds to usability principles [8. Usability engineering offers various process models like the Usability Engineering Lifecycle [18. Figure 1 illustrates the procedure applied in this project which is mainly based on the models described in [5] and [18].

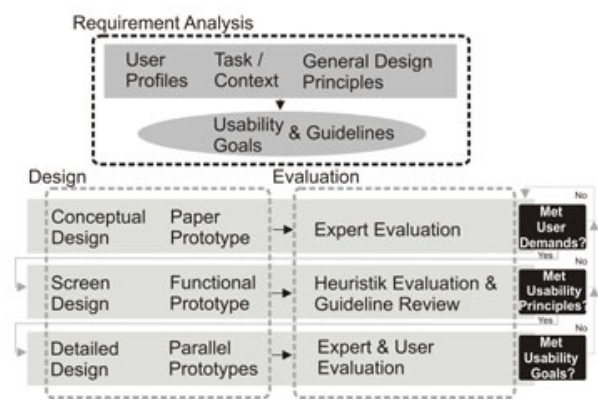

Fig. 1. Two-phased process model underlying the development of the feedback application. It consists of a requirement analysis followed by several levels of design and evaluation (adapted from [5] and [18]).

The development process is comprised of two parts. In the requirement analysis the users will be identified and relevant characteristics will be assessed. In the task and environment analysis the user's major tasks, goals end information needs will be determined. General design principles will be reviewed and principles relevant to the project will be extracted. The obtained information will lead to high-level usability goals driving further design decisions. They will be transfered to more detailed design guidelines that in turn will be specified in project standards. These standards are directly applicable and will be summarized in styleguides. The formulation of a styleguide is an ongoing process requiring refinement as the project progresses.

Based on the results of the requirement analysis the design phase will be entered. It consists of three design levels, each associated with an evaluation action. In the first level of design, major display structures and information visualization ideas will be generated and implemented in a paper prototype. If all respondents agree upon the concept, a screen design prototype will be produced 
and evaluated by a combination of a heuristic evaluation and guideline review based on the usability principles. After a refinement and reevaluation a detailed user interface design will be developed and tested by the users.

\section{Requirement Analysis}

\subsection{General Considerations}

The clinical context imposes some major restrictions concerning the study setting and user group. For the clinical study, two rehabilitation devices will be used: the arm trainer Bi-Manu-Track (BMT) and the Reha-Slide (RS)(see figure 2). The BMT is a microprocessor-controlled device for reproducing active and passive flexion and extension of the wrist as well as pro- and supination of the forearm movements. The RS is used for the treatment of arm, shoulder and elbow by flexion and extension of the elbow, abduction and adduction of the shoulder and rotation of the wrist. (For a comprehensive description of the BMT and RS see [10], 11].)
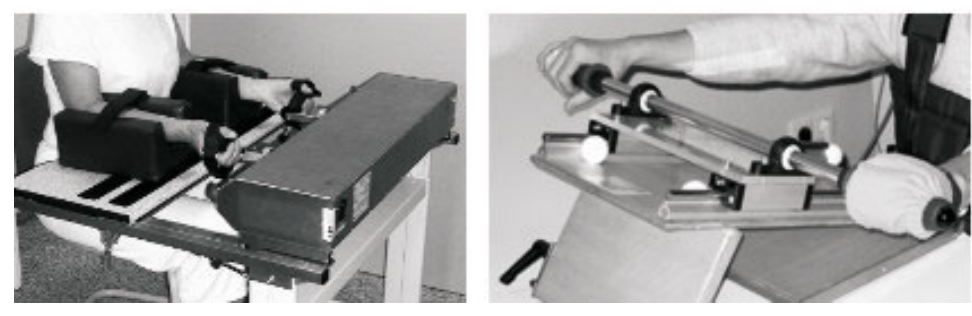

Fig. 2. Bi-Manu-Track (left), Reha-Slide (right)

Only patients who meet certain in- and exclusion criteria are eligible to participate in the device-assisted therapy and clinical study. According to [2] these criteria are: a) minimally functional UE, b) no severe upper limb spasticity, c) no hemiparetic shoulder pain, d) no swollen hand impeding closing the fist, e) no other neurological or orthopedic impairments of the UE, f) mobilized in a wheelchair, g) able to follow therapists instructions, h) a positive single test session in the arm studio, and i) informed consent to participate.

\subsection{Designs, Materials, and Procedures}

User Profiles. The first step in generating user profiles is to define the intended users. This is already done by the criteria described above. However, the patients could significantly differ in characteristics relevant to the user interface design such as preferences, attitudes, skills, knowledge and experience. Representative data about user characteristics are usually collected with user profile questionnaires. In the clinical setting questionnaires are not suitable because most of 
the patients are not able to read and to fill out the form independently due to their cognitive and motor limitations. Therefore, structured interviews based on typical user profile questionnaires are deemed as the best method to get direct, accurate and reliable information. In structured interviews the sequence and wording of each question is fixed providing consistency across all interviewees. Besides, predefined response categories facilitate the formulation of answers. The direct conversation allows the interviewer to be sensitive to misunderstandings or difficulties in speech production.

The used interview guide consists of questions about demography (age, family status, educational background), medical background (previous and current physical or mental dysfunctions, etc.) as well as computer usage (availability of computers, frequency of usage, etc.) and experience (interest in computers, preferences, etc.). Additionally, some adapted items from the TA-EG, a questionnaire about affinity for technical products [14] are included.

The patients were recruited at the arm studio of a rehabilitation center to ensure that they meet the above-noted criteria. The arm studio contains several arm rehabilitation devices to intensify the UE treatment. (For a detailed description of the arm studio see [2.) After getting the approval of the rehabilitation center, the interviews were conducted by two different but trained interviewers. The interview began with a written overall statement of purpose. A cover letter and informed consent was handed to the patients. The patients signed the informed consent and by that declared to voluntarily participate. The interviewers read out load the questions and the patients were free to read along. The interview took on average 30 minutes.

The answers were recorded on the interview guide and immediately classified into the predefined response categories. The data were analyzed according to commonalities of and differences between the users.

Task and Environment Analysis. The task and environment analysis serves as a basis for developing the movement task and strives for a better understanding of the information needs of the patients. Furthermore, information about the therapy schedule to assure a smooth integration of the study session into the tight time plan of the patients can be gained. Implications about general conditions of the study and the detailed study procedure will not be reported here.

The task and environment analysis was conducted by a semi-structured observation. This approach allows the concentration of actions that have been considered as relevant in advance, without missing important events that arise out of the situation. The observation took place in the arm studio. The recruitment of the patients corresponded the procedure described in the user profile section. In case some questions arise, the observations could have been discussed with the mentoring therapist in the arm studio. No videotaping was allowed to avoid the patients feeling uncomfortable.

The observer was instructed to list every action and event in a serial manner and was trained to pay attention to occurring problems and disturbances. The observer should also code all events according to the structured observation 
protocol. Categories in the observation protocol are related to the physical environment, distractions and interruptions as well as events and facts concerning the task. These predefined categories were also used for the data analysis.

General Design Principles. General design principles are fundamentals reflecting knowledge about human information processing and perception [17]. These principles can be used for evaluations in the design and evaluation phase. Project-relevant principles were identified by reviewing commonly cited usability literature like [19], 25], and [21], as well as standards like [4, 3], and [5]. These general principles were translated to project needs based on the specification from the user profiles as well as the task and environment analysis.

\section{Results}

\subsection{User Profiles, Task and Environment Analysis}

12 patients ( $50 \%$ female) participated in the user profile interview ranging in age from 21 to 76 years. Their mean hospitalization was 4 weeks. $41.7 \%$ are married and living with their partners. The educational level is quite high with $58.3 \%$ of the patients having an Abitur or higher. About $75 \%$ of the patients wear corrective lenses and/or suffer from hearing disorders. They also have perceived attentional deficits and speech production difficulties. 91\% could imagine that computers could help and support the motor rehabilitation.

The patients widely differ in their attitudes towards and experience with computers. Two typical user groups could have been identified: experienced and inexperienced users. Prototypical experienced users own a computer and use it on a regular basis at least once a week. They are familiar with word processing and internet. These users are comfortable with the keyboard and computer mouse. They are generally positively attuned to computers and they like learning new computer programs. On the other hand, inexperienced users possess no computer at home, some of them never have used a computer once in their live. They avoid using computers in general and could not imagine to feel comfortable with either of the input devices. They know computer-assisted learning software from their neuropsychological therapy sessions but they are skeptical about the advantages. They are not interested in anything concerning computers and some are even afraid of them. They are also convinced that they will never learn how to deal with computers and computer programs.

The task analysis suggests that there are three main training objectives: extending the range of motion, controlling the motion according to steadiness, a combination of range of motion and steadiness. For the development of the first feedback application, the project team and clinicians agreed to concentrate on the range-of-motion task. A typical task formulation for the BMT could be "Increase your range of motion. Therefore, turn your wrist as far as possible to the right and left." Technically, there are several parameters that can be recorded and visualized such as the maximum range of motion patients are able to reach, current movement, the maximum achieved range of motion, the range of motion 
achieved in the last trial, etc. The decision about the parameters that will be recorded and visualized will be made in the design phase.

The environment analysis showed that the patients are scheduled to their treatments but arrive with an average delay of 10 minutes. The therapist prepares the rehabilitation devices and seats the patients in front of them. The patients absolve their training sessions without any assistance from the therapist. The sessions last a averaged period of 15 to 20 minutes and a total of 100 to 300 repetitions. The therapist returns as soon as the training routine is completed. The task is quite monotone but mentally demanding. Most of the patients are highly distractible and confused as well as easily exhausted and fatigued. Frequently, the therapist has to remind patients to stay awake or to refocus their concentration on the movement task.

\subsection{Usability Goals}

The user profile analysis confirmed previous findings about the prevalence of cognitive deficits affecting the information processing capacity and speed of the patients. Therefore, the feedback application should be supporting rather than further strain the cognitive system. The identification of inexperienced and apprehensive users indicates that the application must be convincing of being helpful and supporting. Thus, the design must be motivating, easy to understand and to use. Most of the patients have some kind of visual disorder and difficulties with visual thinking. Hence, the application must consist of easy to perceive and visible elements without being demanding to the visual system. The monotone movement task and the high distraction sensitivity as well as the rapid tiredness require the adoption of a fine balance between a stimulating and attention attracting application and prevention of interference with the perception and execution of the actual movement. Due to the frequent use, the application should not contain annoying and reoccurring instructions. The usability goals can be summarized as follows:

- The design must support learning without being mentally demanding.

- The design must support inexperienced, anxious users.

- The design must support perceptibility and visibility.

- The design must attract the attention without being interfering.

- The application should support frequent use.

Even if the usability goals help focus the design efforts, they are not measurable and no concrete design alternatives or ideas can be inferred. Based on the remarks above, the usability goals can be broken down in more detailed design principles. These project-specific principles can be amplified with suggestions of the general design principles from the literature review. The key principles identified so far are summarized in table 1.

The principles will be used for heuristic evaluations and as criteria for user tests. In the course of the development the guidelines will be specified and transfered to project standards. As explained above, the standards will be available 
Table 1. Conclusions about major design principles and exemplary guideline suggestions according to the usability goals derived from the requirement analysis

\begin{tabular}{l|l|l}
\hline Principle & Description & Guideline \\
\hline \hline $\begin{array}{l}\text { Suitable for } \\
\text { perception }\end{array}$ & $\begin{array}{l}\text { Elements and objects of the inter- } \\
\text { face must be visible, distinguishable } \\
\text { and readable. }\end{array}$ & $\begin{array}{l}\text { Use high color contrasts, big font } \\
\text { sizes, readable font types, ... . }\end{array}$ \\
\hline $\begin{array}{l}\text { Easy to un- } \\
\text { derstand }\end{array}$ & $\begin{array}{l}\text { The application is comprehensible if } \\
\text { it is self-descriptive, relevant, con- } \\
\text { sistently and clearly structured and } \\
\text { conform with users expectations. }\end{array}$ & $\begin{array}{l}\text { Usemiliar and self-descriptive } \\
\text { colors, shapes and positioning, ... . }\end{array}$ \\
\hline $\begin{array}{l}\text { Suitable for } \\
\text { the task }\end{array}$ & $\begin{array}{l}\text { The application is suitable for the } \\
\text { task if it supports the movement ex- } \\
\text { ecution and learning process effec- } \\
\text { tively and efficiently. }\end{array}$ & $\begin{array}{l}\text { Provide compatibility of input } \\
\text { (movement) and output (feedback), } \\
\text { tion, visualize the information com- } \\
\text { pactly, ... . }\end{array}$ \\
\hline $\begin{array}{l}\text { Suitable for } \\
\text { motivation }\end{array}$ & $\begin{array}{l}\text { The application must be stimulat- } \\
\text { ing and interesting instead of frus- } \\
\text { trating and boring. }\end{array}$ & $\begin{array}{l}\text { Chose parameter values that are en- } \\
\text { vouraing and make improvements } \\
\text { visible, use friendly and pleasant } \\
\text { colors and graphics, ... . }\end{array}$ \\
\hline
\end{tabular}

in a styleguide and can be used for similar applications. For instance the requirement of being suitable for motivation results in the guideline suggesting to use friendly and pleasant colors. The standards could contain specifications about the background color fixed to a concrete hex color value.

\section{Outlook}

This paper suggested to apply a user-centered design approach to develop a user interface for the presentation of movement-related parameters. The application will be used in a clinical feedback study that is aimed to investigate effects and mechanisms of visual, augmented feedback to support the motor learning process after stroke. It was expected of the user-centered design approach to produce an application which is tailored to the special needs of the stroke patients concerning different cognitive and motivational conditions as well as computer attitudes and experiences.

As reported, the first phase of the development process described in figure 1 has been successfully completed. Usability goals, principles and guidelines have been derived. Up to date, the level of conceptional design and expert evaluation as well as the screen design level with the heuristic evaluation and guideline reviewing is completed and the detailed design level has been entered. Currently, work on alternative designs of the application is in progress based on the suggestions of the preceding design levels and evaluations.

The retrieved results and undergone experiences are very encouraging. The adaption of the user-centered approach and the extensive requirement analysis as well as evaluation actions after every design level are paying off. Especially 
the cognitive, perceptual and motor deficits of the stroke patients made an early involvement of the users essential and fruitful. Many important suggestions concerning the design could have been obtained from the users and clinicians. In addition, the intended use of the application in a clinical study necessitates the approval of the clinicians. Therefore, the user-centered approach is a excellent instrument to increase the acceptance amongst the stakeholders.

\section{References}

1. Bray, S., Shimojo, S., ODoherty, J.P.: Direct instrumental conditioning of neural activity using functional magnetic resonance imaging-derived reward feedback. The Journal of Neuroscience 27(28), 7498-7507 (2007)

2. Buschfort, R., Brocke, J., Heß, A., Werner, C., Waldner, A., Hesse, S.: Arm studio to intensify upper limb rehabilitation after stroke: Concept, acceptance, utilization and preliminary clinical results. Jounral of Rehabilitation Medicine 42, 310-314 (2010)

3. CEN: DIN EN ISO 9241-12: Ergonomic requirements for office work with visual display terminals - Part 12: Presentation of information. Beuth Verlag (1998)

4. CEN: DIN EN ISO 9241-110: Ergonomics of human-system interaction- Part 110: Dialogue principles. Beuth Verlag (2006)

5. CEN: DIN EN ISO 9241-210: Ergonomics of human-system interaction - Part 210: Human-centered design for interactive systems. Beuth Verlag (2010)

6. Cirstea, M.C., Levin, M.F.: Compensatory strategies for reaching in stroke. Brain 123, 940-953 (2000)

7. van Dijk, H., Jannink, M.J.A., Hermens, H.J.: Effect of augmented feedback on motor function of the affected upper extremity in rehabilitation patients: A systematic review of randomized controlled trials. Journal of Rehabilitation Medicine 37(4), 202-211 (2005)

8. Dix, A., Finley, J., Abowd, G.D., Beale, R.: Human-computer interaction, 3rd edn. Pearson, New York (2004)

9. Flinn, N.A., Radomsky, M.V.: Occupational therapy for physical dysfunctions. In: Trombly, C.A., Radomsky, M.V. (eds.) Occupational therapy for physical dysfunction, 6th edn., ch.14, pp. 283-297. Lippincott Williams \& Wilkins, Baltimore (2006)

10. Hesse, S., Schulte-Tigges, G., Konrad, M., Bardeleben, A., Werner, C.: Robotassisted arm trainer for the passive and active practice of bilateral forearm and wrist movement in hemiparetic subjects. Archives of Physical Medicine and Rehabilitation 84(6), 915-920 (2003)

11. Hesse, S., Werner, C., Pohl, M., Mehrholz, J., Puzich, U., Krebs, H.I.: Mechanical arm trainer for the treatment of severely affected arm after stroke: A single-blinded randomized trial in two centres. American Journal of Physical Medcine Rehabilitation 87(10), 779-788 (2008)

12. Jokinen, H., Kalska, H., Mäntylä, R., Pohjasvaara, T., Ylikoski, R., Hietanen, M., Salonen, O., Kaste, M., Erkinjuntti, T.: Cognitive profile of subcortical ischaemic vascular disease. Journal of Neurology, Neurosurgery, and Psychiatry 77(1), 28-33 (2006)

13. Kakei, S., Hoffman, D.S., Strick, P.L.: Sensorimotor transformations in cortical motor areas. Neuroscience Research 46, 1-10 (2003) 
14. Karrer, K., Glaser, C., Clemens, C., Bruder, C.: Technikaffinität erfassen - der Fragebogen TA-EG. In: Lichtenstein, A., Stoessel, C., Clemens, C. (eds.) Der Mensch als Mittelpunkt technischer Systeme. 8. Berliner Werkstatt Mensch-MaschineSysteme (ZMMS Spektrum, Reihe 22, Nr. 29), pp. 20-196. VDI Verlag GmbH, Düsseldorf (2009)

15. Magill, R.A.: Motor learning and control - Concepts and applications, 7th edn. McGraw-Hill, New York (2007)

16. Marschall, F., Daugs, R.: Feedback. In: Mechling, H., Munzert, J. (eds.) Handbuch Bewegungswissenschaft - Bewegungslehre, ch. D.2, pp. 281-294. Hofmann, Schorndorf (2003)

17. Mayhew, D.: A design process for web usability. In: Proctor, R.W., Vu, K.-P.L. (eds.) The Handbook of Human Factors in Web Design, ch.19, pp. 338-356. Lawrence Erlbaum Associates, Mahwah (2005)

18. Mayhew, D.J.: The usability engineering lifecycle: A practitioner's handbook for for user interface design. Morgan Kaufmann, San Francisco (1999)

19. Nielsen, J.: Usability engineering. Morgan Kaufmann, San Francisco (1993)

20. Pohl, M., Werner, C., Holzgraefe, M., Kroczek, G., Mehrholz, J., Wingendorf, I.: Repetitive locomotor training and physiotherapy improve walking and basic activities of daily living after stroke: A single-blind, randomised multi-centre trial. Clinical Rehabilitation 1, 17-27 (2007)

21. Preiser, W., Smith, K.H.: Handbook of universal design, 2nd edn. McGraw-Hill, New York (2010)

22. Rosamond, W., Flegal, K., et al.: Heart disease and stroke statistics-2008 update: A report from the American Heart Association statistics committee and stroke statistics subcommittee. Circulation 117, e25-e146(2008)

23. Saxena, S.K.: Prevalence and correlates of cognitive impairment in stroke patients in a rehabilitation setting. International Journal of Psychosocial Rehabilitation 10(2), 37-47 (2006)

24. Schmidt, R.A., Lee, T.D.: Motor control and learning. Human Kinetics, Champaign/Ill (2005)

25. Shneiderman, B., Plaisant, C.: Designing the user interface: Strategies for effective human-computer interaction, 5th edn. Addison-Wesley Longman Publishing Co., Boston (2010)

26. Subramanian, S.K., Massie, C.L., Malcolm, M.P., Levin, M.F.: Does provision of extrinsic feedback result in improved motor learning in the upper limb poststroke? A systematic review of the evidence. Neurorehabilitation and Neural Repair 24(2), 113-124 (2010)

27. Truelsen, R.B., Mathers, C., Boudousslavsky, J., Boysen, G., Piechowski-Józwiak, B.: Stroke incidence and prevalence in Europe: A review of available data. European Journal of Neurology 13, 581-598 (2006)

28. van Vliet, P.M., Wulf, G.: Extrinsic feedback for motor learning after stroke: what is the evidence? Disability and rehabilitation 28(13-14), 831-840 (2006)

29. Winstein, C.J., Merians, A.S., Sullivan, K.J.: Motor learning after unilateral brain damage. Neuropsychologica 37, 975-987 (1999) 